\title{
Toward a Theory of Informing Objects
}

\author{
Robert Joseph Skovira \\ Robert Morris University, Moon Twp, PA, USA
}

\author{
skovira@rmu.edu
}

\begin{abstract}
This essay is a delineation of some ideas associated with the concept of informing object as a methodological unit of description and analysis of documents and other things used by members of communities of discourse and practice in social-cultural environments. The essay argues that an informing object is a sense-making artifact of a social group and attending system of meanings and used pragmatically and normatively within common situations. The paper presents and discusses some putative attributes of an informing object as a means to describing and analyzing contexts of information and communication technologies.
\end{abstract}

Key words; informing object, artifact, informing system, community of discourse and practice

\section{Introduction}

We live with things, documents, reports, forms-to-be-filled-out, even screens-as-interfaces; these things of our event worlds (Debons, 2008) are artifacts within the social-cultural environments of our communities of discourse and practice. These things stand, and are used, are understood, in the midst of communities of discourse and practice. These things are indexed and named in discourse and practice; they are parts of vocabularies, practices. They symbolize and ritualize possible action allowed or constrained. They are structuring elements of situations. These things with which we live are meaningful; they are meaningful in terms of their potential and actual uses within situations (Dewey, 1986).

As artifacts (Simon, 1981), they are informing objects designed to particular purposes or ends of situations. An informing object is always recognized, is sensible, because of the social-cultural situations in which it is used, and because of its presence in its social-cultural matrix. An informing object realizes the ecology, the system of informing. It is an element of an informing system, an holistic environment. An object informs because of its relationship to other objects, perhaps roles and statuses of positions of people, practices or processes, vocabularies, all of which are locatable in the same space, i.e., the social-cultural environment or infoscape. Perhaps this is another way of saying that an object is a sign or signifier of a social-cultural frame, situation, practice or vocabulary. And through them, it is a sign of the social-cultural complex, the infoscape, itself.

Material published as part of this publication, either on-line or in print, is copyrighted by the Informing Science Institute. Permission to make digital or paper copy of part or all of these works for personal or classroom use is granted without fee provided that the copies are not made or distributed for profit or commercial advantage AND that copies 1) bear this notice in full and 2) give the full citation on the first page. It is permissible to abstract these works so long as credit is given. To copy in all other cases or to republish or to post on a server or to redistribute to lists requires specific permission and payment of a fee. Contact 0HPublisher@InformingScience.org to request redistribution permission.

\section{Purpose of the Essay}

This essay is a delineation and definition of some ideas associated with the concept of informing object as a methodological unit of description and analysis of documents and other things used in social-cultural environments as elements of informing systems. An informing object is a kind of methodological fiction. 
Anything can inform, can signify a sense, can be symbolic, given the situation, given the communities of discourse and practice involved (Eco, 1976; Liu, 2000). The essay discusses a conceptualization of an affair to aid in understanding the interaction and use of informational symbols and rituals within situations of communities of discourse and practice. The idea as a descriptive and analytic instrumental is based in a natural sense of how we use things in our everyday affairs. Because an informing object is, in this view, a social-cultural structure, the essay first discusses a conceptualization of social-cultural environment as infoscape (Skovira, 2004), and then of community of discourse and practice (Brown \& Duguid, 2000; Dewey, 1986), and then a conceptualization of informing object.

\section{Social-cultural Environment}

A social-cultural matrix consists of multiple communities of practice and discourse encapsulating multiple frames (systems of meanings or definitions of situations) sometimes competitive and oppositional, which encapsulate situations, practices and vocabularies. Situations, practices and vocabularies encapsulate doings and sayings of everyday actions. Doings and sayings are instances of types of practices and vocabularies. They make practices and vocabularies visible (Eco, 1976; Geertz, 1973; Goffman, 1974; Hall, 1981; Hall \& Hall, 1990; MacIntyre, 1966).

A social-cultural matrix is a multi-layered complex (Hofstede \& Hofstede, 2005; Karahanna, Evaristo, \& Strite, 2005). It is an infoscape (Skovira, 2004). This layered environment consists of multiple communities of discourse and practice. Each layer consists of social networks of association and attending systems of meanings or frames which encapsulate or define situations, practices and vocabularies. A frame (a system of meanings or a set of conceptualizations, an ontology) as a semantic structure (a meaning structure) encapsulates logically a set of practices (documented as procedures) and a vocabulary (documented as a set of taxonomies representing conceptualizations, dictionaries and thesauri). Taxonomies, dictionaries and thesauri make a vocabulary visible; procedures (documented descriptive rules-of-action, i.e., how-to-dos) make visible practices. Social-cultural environments ground situations, practices and vocabularies and define fields of action which provide space for personal idiosyncratic stylistic takes and turns of basic frames defining everyday doings and sayings (Brown \& Duguid, 2000; Dewey, 1986; Gannon, 2001; Kostelnick \& Hassett, 2003; G. Lakoff \& Johnson, 1980; R. T. Lakoff, 2000; Spradley, 1980; Spradley \& McCurdy, 1972; Trompenaars, 1994; Trompenaars \& Woolliams, 2003).

\section{Community of Discourse and Practice}

Communities of practice and discourse reside, within the various layers of a social-cultural multivariate complex or infoscape. They function as translators of relationships and attending systems of meaning; they are transactional in nature. A community of practice and discourse place boundaries upon situations. Situations (physical) and attending definitions of the situations (logical) in turn bound vocabularies and practices. The logic of a situation is its frame, or definition. A community of practice and discourse is a transactional affair, a translator of a social-cultural layer by, in which a person grounds his or her behavior in the immediate social-cultural layer and in the social-cultural matrix or infoscape.

In any situation, a person interacting is in the process of translating the senses of frames, the situations-at-hand, practices and vocabularies. A person works within a genealogy, a tradition within a community of discourse and practice. These are transactional. What a person knows, what a person recognizes, the objects which inform and are used, he or she knows because of where he or she is. Where he or she is, is the community of practice and discourse in a social-cultural complex. A person (role, status, styles) resides, is located within his or her community (communities) of practice and discourse (Rowe \& Mason, 1989). 


\section{An Example of an Informing Object}

The Institutional Review Board (IRB), its members, is meeting. On the agenda for this particular meeting is a review of the IRB research proposal form which anyone wishing to do research must fill out and submit for review. It is a re-doing of the form, as an informing object, adjusting and aligning the form's categories, and their meanings, to provide a better sense of the type and possible impact on human subjects of the research. The review is linear and sequential, beginning from the top of the form. As the group works its way through the form, questions arise, and observations are made, and meanings are defined. The sense of the form is worked out in a public manner but grounded in transacting communities of discourse and practice. Members of this community come to this sense-making situation (Dervin, 1999) from their respective teaching and research communities of practice and discourse.

The IRB, like any long-standing committee or team, as a social-cultural environment, is a community of discourse and practice. As a social group with an attending system of meanings, it has its own vocabulary and ways of doing things, by which its affairs are made common, talked about, acted upon. As an institutional entity, it is a public physical and informational structure existing within a larger organizational framework. It is more a logical or informational communal structure because many of its decisions (acts) are made in a distributive manner, disembodied from its physical coming together in a physical location. The members of this community of practice and discourse come from across the institution. They represent multiple communities of practice and discourse: their respective schools: library, communications and information systems, nursing and allied health, business, education and social sciences, and their respective departments indicating their teaching and research perspectives. The IRB meeting is a complex multivocal social-cultural environment; an infoscape of competing and conflicting senses or reconstructions of senses about types of situations, kinds of practices and differing vocabularies used to talk about and make common (communicate) what things and words mean (Dewey, 1986, p. 52). As a community of practice and discourse, the IRB is about the reviewing of universitywide research proposals in terms of the possible potential harm which any research might do to the human subjects of the research.

\section{A Second Example of an Informing Object}

Another instance of an informing object is the Faculty Annual Report form which when completed serves as a performance review document and basis for granting merit pay. The form has three major categories: Scholarship, teaching, and service. This form when filled out functions as a semantic structure at the intersection of multiple communities of discourse and practice. It is an informing object of allowances and constraints, defining what is real (category A journals) and what is not.

This informing object, the FAR, as the IRB proposal form, is a result of negotiation between communities of discourse and practice (in the abstract: Administration and faculty union) consisting of various administrative layers and within departments, layers of rank and disciplinary orientations of professors. These communal layers of practice and discourse constitute the institution's social-cultural environment or infoscape. The FAR, as informing object, is sensible only in this context and is an important semantic structure of the reality of the environment.

\section{Conceptualizing Informing Object}

Borgmann (1999) writes that social-cultural affairs or things are "objects of information" (p. 75). More to the point, an informing object subsists in a situation, articulating a vision of its situation (Dewey, 1986, pp. 72-73). As Devlin (1999) writes: "An object in the world can represent information by virtue of that object being in a situation of a certain type" (p. 41). Further, an informing 
object is a kind of "artifact" (Nardi \& O'Day, 1996), where this notion resonates with Simon's (1981) idea: "An artifact can be thought of as a meeting point - an 'interface' in today's terms between an 'inner' environment, the substance and organization of the artifact itself, and an 'outer' environment, the surroundings in which it operates" (p. 9). An informing object, as any document, report, form-to-be-filled-out, for example, a Faculty Annual Report (FAR) (Skovira, 2008a) or an Internal Review Board (IRB) research proposal form, has a practical sense only within a community of practice and discourse. Objects inform as signs of shared (shareable) meaning (Eco, 1976; Spradley \& McCurdy, 1972) which are explanations, interpretants of possible senses, embodied in various (and variable) communities of discourse and practice. The meaning is not psychological; it is social-cultural; an informing object sits in a complex multivariate location, a logic, a space; an instance of encapsulating social-cultural frames, and an organizer of experience.

\section{Situational Symbolism}

An informing object ritualizes its informing as part of the action of a situation; it is symbolic of a common understanding of the end for which it is used in a situation (Blumer, 1998). It has a semiotic functionality (Eco, 1976; Liu, 2000). The informing object is an anthropological (cultural, ethnosemantic) thing of sense making (Spradley, 1980; Spradley \& McCurdy, 1972). Informing objects are results (and consequences) of communities of action (Dewey, 1986) or practice (Brown \& Duguid, 2000), which is to say, social groups sharing (in doing and saying) publicly expressed practices and meanings (Geertz, 1973).

As an informational symbol, an informing object forms an intersection of multiple intersubjectivities (Percy, 1975; Turner, 1967, 1974) and personal idiosyncratic re-constructions of lived-in communities of practice and discourse. It is an object-of-meaning using circumstantial information (context) and present (past, future) activities and events, shaping meaning recognizable to the community of practice and discourse which is the object's warrant and ground.

An informing object as an informational symbol and ritual focuses the complex multivocal socialcultural environment into a particular and usable shape (Hofstede \& Hofstede, 2005; Turner, 1967, 1974). It is a re-construction of intersubjectivities (Percy, 1975), represented by diverse practices (how we do things) and vocabularies (how we talk about things) into a univocal affair. An informing object re-constructs multiple and multivalued aspects of a situation into a common, and now communicable, state-of-affairs. It makes common sense for a community of discourse and practice out of sometimes competing and conflicting common senses of multiple constitutive intersubjectivities.

\section{Communicational Artifact}

An informing object is a communicative object, or artifact (Drucker, 1970; Hall, 1981; Simon, 1981). An informing object is a metaphor of a social-cultural game, rhetorical in its import (Hauser, 1991; Hofstede \& Hofstede, 2005; G. Lakoff \& Johnson, 1980). An informing object is a genealogy of action, activities and events commonly understandable to members of a community. It is a transformer and organizer of private experience into a form of common experience.

\section{Public Take}

As a public affair, an informing object is a public "take" (Geertz, 1973; R. T. Lakoff, 2000). A public take is specific to the community of practice and discourse and serves as a focal ritual or symbol for members of the community (Turner, 1967, 1974). It is a way of dealing with events or activities. A public take, as an informing object, makes private experience public, makes them real. An informing object as a public take makes explicit theories-in-use (Argyris, 1999; Argyris 
\& Schön, 1996). An informing object is a public valuing. An informing object is not a private artifact. An informing object ritualizes or symbolizes idiosyncratic private experience. It is an intersubjective semantic structure (Percy, 1975).

As a public take, an informing object is a re-construction of diverse ontologies (the Whats of a community of discourse and practice) and their attending meanings (the Whys and Hows) into a common ontology for a particular community of discourse and practice (Davenport \& Prusak, 2000; Senge, 1990). An informing object, when named, represents a gestalt of details; the details are of use only in situations recognized by a community of practice and discourse. An informing object represents a kind of "social contract" (Skovira, 2008b), a re-construction of an affair. A social contract, implicit or explicit, is a shared agreement basic to a situation and its circumstances, results and consequences.

\section{Logical Location}

An informing object, e.g., the IRB research proposal form, the FAR, is located in a community of discourse and practice, which is itself located in a social-cultural landscape, an infoscape, of an organization (itself a complex multivocal social-cultural environment consisting of communities of discourse and practice). It creates a logical space for interaction. Informing objects reference social-cultural environings, making perceptible as sensible everyday things in the world. An informing object is a way by which a community of discourse and practice makes real the structures of action, events and activities.

An informing object also locates the persons involved in their respected communities of discourse and practice. They are the stuff of experience. They are things realized within the commonalities of associative personal networks and systems of meanings, in situations via practices and vocabularies. As R. T. Lakoff (2000) writes: "We must see ourselves, in all our language-using roles, as participants in several always shifting communities of meaning-making" (p. 13). An informing object is a way by which members of a community of discourse and practice (or interacting communities) make real the structures of action, activities and events; it is a real affair of communal logic.

\section{Informational Design}

Designing an artifact or informing object as an everyday thing is designing it as a part of a practice or discourse. A designed artifact references a practice or discourse as an element of an informing system. The practice or discourse, the informing system, is its grounding, its interpretant or explainer (Jacobson, 1999; Kostelnick \& Hassett, 2003). An informing object is an artifact of ends-in-view; it is teleological in its affects. These objectives can become evaluative criteria. An informing object infers a structure also by which the event or activity informed about can be judged; the structure is a set of criteria, usually tacit. They are embedded in the object.

\section{Conclusion}

An informing object as a physical artifact resides and works within communities of discourse and practice and social-cultural environments. We live with them. They make up our informing systems. They are communicational devices between interacting communities of discourse and practice. They structure and organize our experience by realizing our actions. They represent genealogical events, creative of personal and institutional memories. An informing object describes, is an instrument of describing the experienced, and in the describing it is always an instrument of explaining, of analyzing. An informing object, which can be used to lie $(E c o, 1976)$ is a sign of a semiotic situation. Metaphorically, an informing object is a "matuzka" doll. 


\section{References}

Argyris, C. (1999). On organizational learning ( $2^{\text {nd }}$ ed). Oxford: Blackwell. (first published in 1992.)

Argyris, C., \& Schön, D. A. (1996). Organizational learning II: Theory, method, practice. Reading, MA: Addison-Wesley.

Blumer, H. (1998). Symbolic interactionism: Perspective and method. Berkeley: University of California Press. (Original work published 1969).

Borgmann, A. (1999). Holding on to reality: The nature of information at the turn of the millennium. Chicago: The University of Chicago Press.

Brown, J. S., \& Duguid, P. (2000). The social life of information. Boston: Harvard Business School Press.

Davenport, T. H., \& Prusak, L. (2000). Working knowledge: How organizations manage what they know. Boston MA: Harvard Business School Press.

Debons, A. (2008). Information science 101. Lanham, MD: Rowman \& Littlefield.

Dervin, B. (1999). Chaos, order, and sense-making: A proposed theory for information design. In R. Jacobson, (Ed.). Information design (pp. 35-57). Cambridge, MA, and London: The MIT Press.

Devlin, K. (1999). InfoSense: Turning information into knowledge. New York: Freeman.

Dewey, J. (1986). Logic: The theory of inquiry. In J. A. Boydston (Ed.), John Dewey: The later works, 1925-1953 (Vol. 12: 1938). Carbondale and Edwardsville: Southern Illinois University Press. (Original work published 1938).

Drucker, P. F. (1970). Technology, management, and society. New York: Harper \& Row.

Eco, U. (1976). A theory of semiotics. Bloomington, IN: Indiana University Press.

Gannon, M. J. (2001). Understanding global cultures: Metaphorical journeys through 23 countries $\left(2^{\text {nd }}\right.$ ed). Thousand Oakes, CA: Sage.

Geertz, C. (1973). The interpretation of cultures. New York: Basic Books.

Goffman, E. (1974). Frame analysis: An essay on the organization of experience. Cambridge: Harvard University Press.

Hall, E. T. (1981). Beyond culture. New York: Anchor Books Random House.

Hall, E. T., \& Hall, M. R. (1990). Understanding cultural differences. Yarmouth, ME: Intercultural Press.

Hauser, G. A. (1991). Introduction to rhetorical theory. Prospect Heights, IL: Waveland Press.

Hofstede, G., \& Hofstede, G. J. (2005). Cultures and organizations: Software of the mind. New York: McGraw-Hill.

Jacobson, R. (1999). Introduction: Why information design matters. In R. Jacobson (Ed.), Information design (pp. 1-10). Cambridge, MA and London: The MIT Press.

Karahanna, E., Evaristo, J. R., \& Strite, M. (2005). Levels of culture and individual behavior: An integrative perspective. Journal of Global Information Management, 13(2), 1 - 19

Kostelnick, C., \& Hassett, M. (2003). Shaping information: The rhetoric of visual conventions. Carbondale, IL: Southern Illinois University Press.

Lakoff, G., \& Johnson, M. (1980). Metaphors we live by. Chicago and London: The University of Chicago Press.

Lakoff, R. T. (2000). The language war. Berkeley: University of California Press.

Liu, K. (2000). Semiotics in information systems engineering. Cambridge: Cambridge University Press.

MacIntyre, A. (1966). A short history of ethics. New York: Touchstone Simon \& Schuster. 
Nardi, B. A. \& O’Day, V. L. (1999). Information ecologies: Using technology with heart. Cambridge, MA London: The MIT Press.

Percy, W. (1975). The message in the bottle; How queer man is, how queer language is, and what one has to do with the other. New York: Farrar, Straus and Giroux.

Rowe, A. J., \& Mason, R. O. (1989). Managing with style: A guide to understanding, assessing, and improving decision making. San Francisco, CA: Jossey-Bass.

Senge, P. M. (1990). The fifth discipline: The art and practice of the leaning organization. New York: Currency Doubleday.

Simon, H. A. (1981). The sciences of the artificial $\left(2^{\text {nd }}\right.$ ed). Cambridge, MA: The MIT Press. (Original work published 1969).

Skovira, R. J. (2004). Using informational landscape as a model to understand information use and design within organizations. Issues in Information Systems, V(1), 308-314.

Skovira, R. J. (2008a). Analyzing power as information in organizations: Thinking about how to do it. Issues in Information Systems, VIII(2), 369-377.

Skovira, R. J. (2008b). The social contract revised: Obligation and responsibility in the information society. In H. Nemati (Ed.), Information security and ethics: Concepts, methodologies, tools, and applications (pp. 2797-2813). Hershey New York: Information Science Research.

Spradley, J. P. (1980). Participant observation. New York: Wadsworth Thomson Learning.

Spradley, J. P., \& McCurdy, D. W. (1972). The cultural experience: Ethnography in complex society. Prospect Heights, IL: Waveland Press.

Trompenaars, F. (1994). Riding the waves of culture: Understanding diversity in global business. London: The Economist Books.

Trompenaars, F., \& Woolliams, P. (2003). Business across cultures. Chichester, England: Capstone.

Turner, V. (1967). The forest of symbols: Aspects of Ndembu ritual. Ithaca and London: Cornell University Press.

Turner, V. (1974). Dramas, fields, and metaphors: Symbolic action in human society. Ithaca and London: Cornell University Press.

\section{Biography}

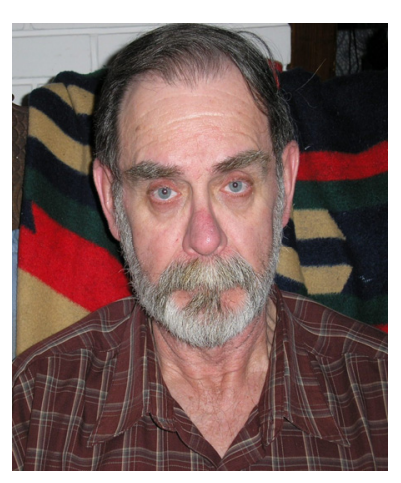

Robert Joseph Skovira is University Professor of Computer and Information Systems in the Department of Computer and Information Systems at Robert Morris University, Moon Twp (Pittsburgh) PA USA. He has taught undergraduate and graduate (MS) courses including Java Programming, Secure Programming, Global, Economic, Social, and Ethical Issues of Computing, Decision Support Systems, Information Design, Ethical and Legal Issues of Technology, and Impact of Technology. In the Doctor of Science program, he has taught Ethnography of Information Systems, Readings in Information Systems and Communications Research, and Writing the Proposal for Research courses. He has been a visiting professor at Comenius University, Bratislava, Slovakia, in 1997 and 2006. Research interests include the anthropology of information, information and information system use within organizations (the infoscape, politics of information, information system bias), cultural and moral frameworks of information and information use, decision making and knowledge management, informing objects, information design and thinking visually. 